\title{
Experimental Research on Behaviour of 3D Printed Gripper Soft Jaws
}

\author{
DRAGOS-FLORIN CHITARIU ${ }^{1}$, EMILIAN PADURARU ${ }^{1}$, GURES DOGAN ${ }^{1}$, \\ MEHMET ILHAN ${ }^{1}$, FLORIN NEGOESCU ${ }^{1}$, CATALIN-GABRIEL DUMITRAS ${ }^{1}$, \\ ADRIAN BEZNEA ${ }^{2 *}$, VICTORITA STEFANESCU ${ }^{2 *}$, IULIAN CONSTANTIN², \\ SORIN BERBECE ${ }^{2}$, MIHAITA HORODINCA ${ }^{1}$ \\ ${ }^{1}$ Gheorghe Asachi Technical University of Iasi, Department of Machine Machine-Tool and Tools, 59A Prof.dr.doc. D. \\ Mangeron Str., 700050, Iasi, Romania \\ ${ }^{2}$ Dunarea de Jos University of Galati, Medicine and Pharmacy Faculty, 47 Domneasta Str., 800008, Galati, Romania
}

\begin{abstract}
In this paper, the problem of the behaviour of soft jaws that can be used to replace the steel jaws of grippers is studied. One of the advantages of additive manufacturing is the printing of fully functional parts. Choice of material is often related to the part strength. The mechanical properties of $3 D$ printed parts should meet the service loading and, also, must be comparable with parts produced by traditional manufacturing techniques - machined parts or injection moulding. From the specialized literature information regarding the test results for effect of various printing parameters on part strength are available made in laboratory conditions and for standard test sample. For ABS materials various values for Young module are presented varying from $1.5 \mathrm{GPa}$ to $2.15 \mathrm{GPa}$, for $100 \%$ infill rate and various modified parameters such as raster orientation. In order to study the behaviour of soft gripper jaws several part were printing and the resistance to bending was tested, by simulating the way a gripper works. An experimental stand was built using a force transducer and a displacement transducer to measure the deformation of the jaw, obtained by $3 D$ printing, under load. The mechanical elastic hysteresis loop during an experimental loading/unloading was plotted and the amount of mechanical energy lost during a cycle, dissipated because the internal friction, was determined. Finite element analysis method was applied to make a comparison with the experimental results. In the finite element analysis, several simulations were considered, varying Young's modulus for the tested material
\end{abstract}

Keywords: gripper jaws, 3D printing, Experimental tests

\section{Introduction}

Grippers are used for orientation-positioning and tightening of the object / part during handling, processing, control and assembly. To ensure the fulfilment of the functions presented, the materials used in the construction of devices and grippers are usually alloy steel. The requirements of grippers are similar to those of clamping fixtures, namely: precise orientation and positioning according to machining requirements, rigidity depending on the size of the workpiece and machining forces, reliability, low maintenance, standardized components, high productivity, costs low [1]. To ensure the performance of the functions presented, the materials used in the construction of devices and grippers are usually alloy steel with an HRC hardness of up to 55-60 HRC for the clamping components.

There are also cases where "flexible" jaws / soft jaws are needed to reduce the deformation of workpieces, especially for thin-walled thin parts when clamping. Soft jaws are one of the simplest methods of customized workholding and can be machined to the negative shape of the workpiece.

Soft jaws can be manufactured by Additive Manufacturing (AM) methods by benefiting from the maximization of the flexibility offered by this method of manufacturing parts [2]. Additive Manufacturing (AM) is defined by the American Society for Testing and Materials as "the process of joining materials to make objects from 3D model data, usually layer by layer" [3, 4].

*email: adrianbeznea@hotmail.com,victorita_stefanescu@yahoo.com 
One of the advantages of AM is the printing of fully functional parts. Choice of material is often related to the part strength. The mechanical properties of $3 \mathrm{D}$ printed parts should meet the service loading and, also, must be comparable with parts produced by traditional manufacturing techniques machined parts, for metal 3D printing or injection moulding thermoplastic [5, 6]. Most metal AM processes create parts with poor surface finish, usually no more than $15 \mu \mathrm{m} \mathrm{Rz}$ and very often considerably reduced. Machine finishing is necessary as a post-process [5]. Thermoplastic 3D printing can achieve good quality surfaces [7].

From the specialized literature information regarding the test results for effect of various printing parameters such as: layer thickness, raster angle, build orientations, fill pattern, printing directions, infill rates and infill patterns air gap and model build temperature, made in laboratory conditions, for standard test sample on part strength are available [5, 6, 8-11].

Dudescu tested the influence of the raster orientation and of the infill pattern and the results indicate a Young's modulus corresponding to the parts with infill percentage from $982 \mathrm{MPa}$ at $20 \%$ to $1503 \mathrm{MPa}$ at $100 \%$, for $\mathrm{ABS}$. The influence of the raster orientation for test parts with $100 \%$ infill rate have a constant value around $1500 \mathrm{MPa}$ [6].

From experimental research Ahmed determined the flexural strength for ABS test sample and obtained 31.50 MPa Ultimate Flexural Stress at a loading of 58 daN and a Deflection at Ultimate Load of $5.96 \mathrm{~mm}$ [11].

$\mathrm{Wu}$ determine experimentally that the value for the elastic limit for ABS obtained was 22.9 MPa and the tensile strength for ABS was 27.1 MPa. The tensile properties of 3D-printed ABS test samples were lower than test samples obtained by injection-moulding by $26.2 \%$ for the elastic limit and by $26.8 \%$ for the tensile strength. The bending strength of ABS determined was $48.6 \mathrm{MPa}$. The 3D-printed ABS test samples had bending strength and bending modulus reduced by up to $8.2 \%$ and $20.8 \%$, respectively, compared with those obtained by injection-moulding [8].

\section{Materials and methods}

In order to analyze the behaviour of the $3 \mathrm{D}$ printed gripper jaws, based on the presented previous research, jaw from a De-sta-co gripper model De-sta-co 84A3-3300AAAA was 3D printed, Figure 1.

Based on the versatility of the printing process the jaw was designed to clamp a can of soft drink.

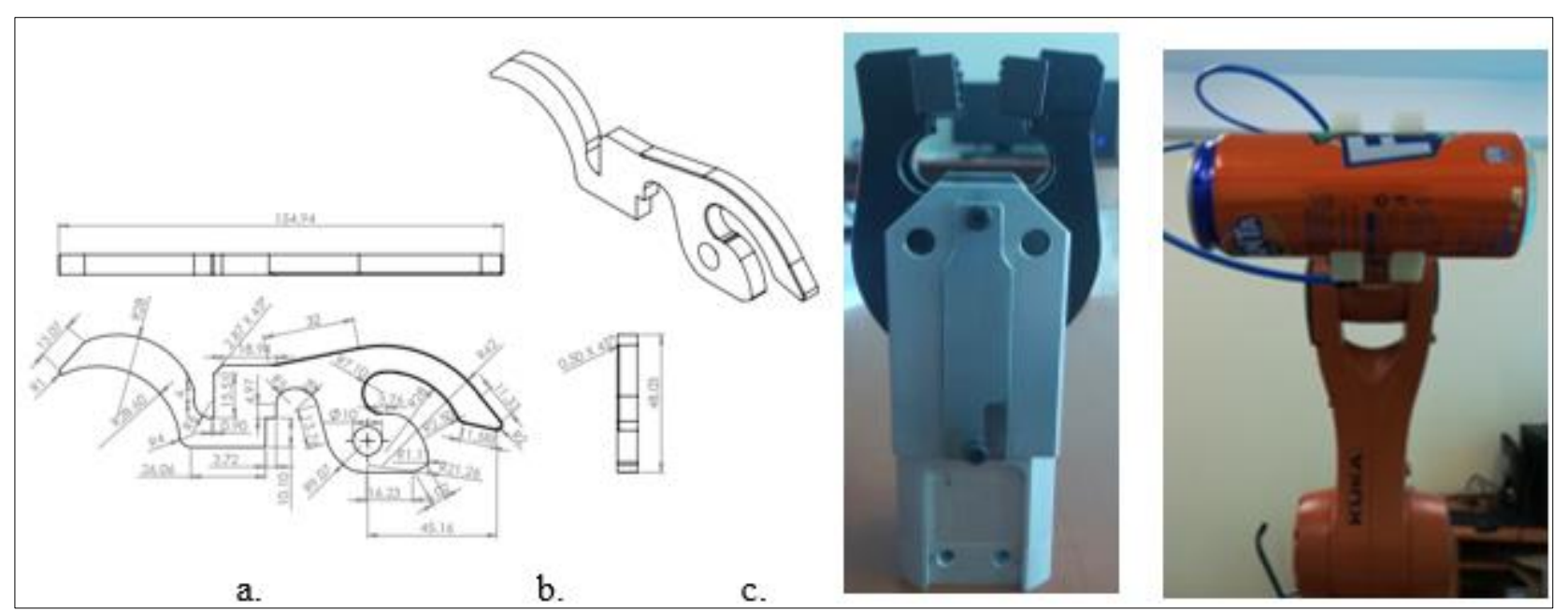

Figure 1. a. View of the 3D printed gripper jaw, b. De-sta-co gripper, c. view of the clamped soda can

In the experiments ABS plus P-430-Acrylonitrile-Butadiene-Styrene production-grade thermoplastic was used to $3 \mathrm{D}$ print the gripper soft jaws. The mechanical properties of the ABS plus P-430 thermoplastic are presented in Table 1, [12]. 
Table 1. Main Mechanical Properties for ABS

plus P-430 thermoplastic [12]

\begin{tabular}{|c|c|}
\hline Mechanical Properties & Value \\
\hline Tensile Strength, Yield & $26 \mathrm{MPa}$ \\
\hline Tensile Modulus & $2,180 \mathrm{MPa}$ \\
\hline Tensile Elongation at Break & $2 \%$ \\
\hline Flexural Strength & $48 \mathrm{MPa}$ \\
\hline Flexural Modulus & $1,760 \mathrm{MPa}$ \\
\hline Rockwell Hardness & $109.5 \mathrm{HRC}$ \\
\hline
\end{tabular}

The pre-processing of the STL model was realized in the 3D printer Insight command software for selecting the appropriate printing parameters. A view of the tool paths used for 3D printing is presented in Figure 2.

The printer used is Stratasys Fortus $250 \mathrm{mc}$, that uses Fused Deposition Modelling (FDM) technology to build parts from the bottom up with precisely deposited layers of modelling and support material, with the following features: ABS plus P-430 - production-grade thermoplastic and soluble support material, build envelope - 254 × 254 × $305 \mathrm{~mm}$, three layer thicknesses $0.178,0.254$ and 0.330 $\mathrm{mm}$.

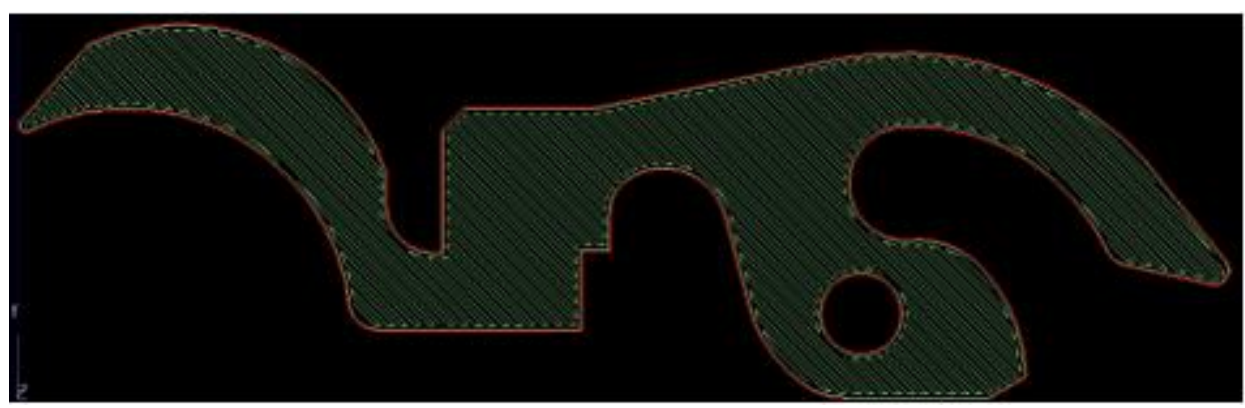

Figure 2. View of the tool paths used for 3D printing

Printing parameters were selected according to the recommendation from specialty literature and considering the machine maximum possibilities: 1 . parts slicing (on $\mathrm{z}$ axis): $0.254 \mathrm{~mm} ; 2$.visible surface raster: $0.3556 \mathrm{~mm} ; 3$. internal raster: $0.3556 \mathrm{~mm}$; 4. raster angle: 0; 5.part raster width: $0.3556,6$ part interior style solid.

After printing the jaws in accordance with the printing parameters mentioned above, the jaws were mounted in a test stand that simulated the loading of one in the gripper.

The acting force is measured with the force transducer and simulates the effect of the clamped part. The elastic deformation was measured by using and displacement transducer.

The measuring equipment presented in Figure 3 consists of: force transducer $S 95 \mathrm{kN}$ produced by Hottinger Baldwin Messtechnik; inductive displacement transducer type Wl/10mm $-10 \mathrm{~mm}$ stroke, produced by Hottinger Baldwin Messtechnik; Spider 8 multi-channel electronic PC measurement unit produced by Hottinger Baldwin Messtechnik; computer. 


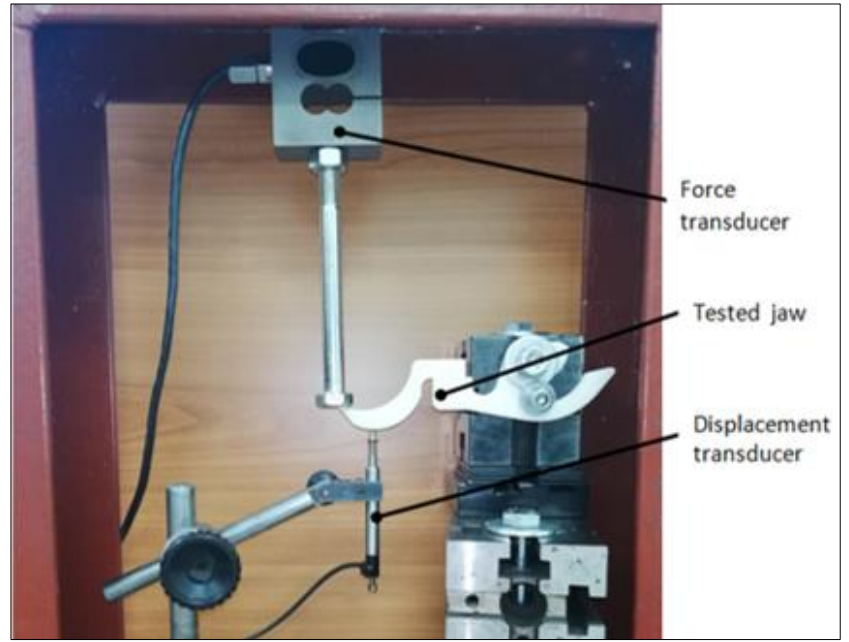

Figure 3. Test stand

\section{Results and discussions}

Figure 4 shows the hysteresis behaviour (force $F$ versus deformation $d$ evolution) during three successive cycles of gripper jaw loading/unloading, with three consecutive elastic mechanical hysteresis loops characterized by relative high deformations.

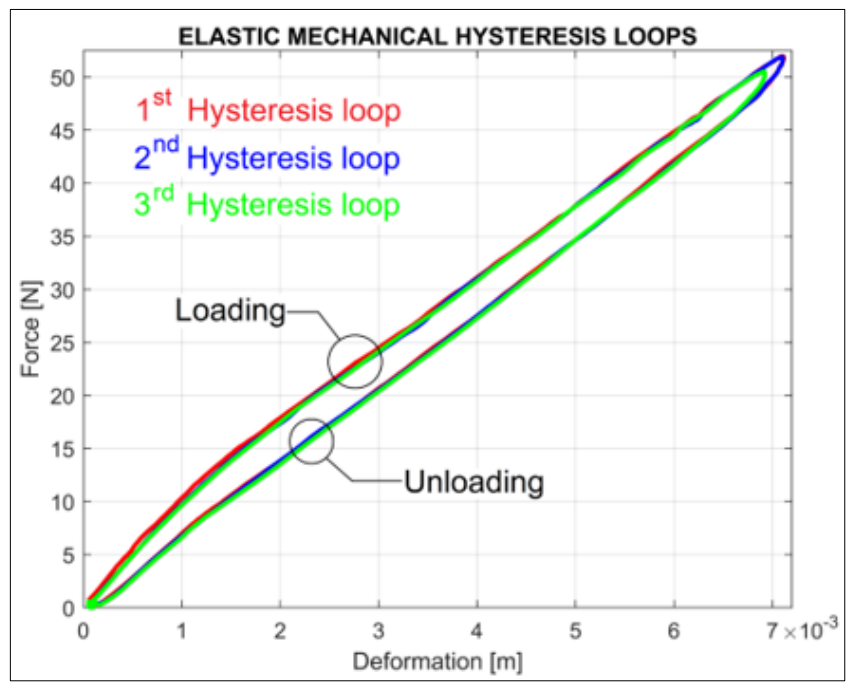

Figure 4. The description of mechanical hysteresis loops for the 3D printed gripper jaw

It is obvious that there are big similarities between these loops (shape and size). The analysis of each hysteresis loop produces some interesting results.

Figure 5 shows the first mechanical elastic hysteresis loop during an experimental loading/unloading cycle with a force range: $0 \div 52 \mathrm{~N}$ and a deformation range: $0 \div 7.12 \mathrm{~mm}$.

First important experimental information available here is the area of hysteresis loop $(0.02285 \mathrm{~N} \cdot \mathrm{m})$. This area is exactly the amount of mechanical energy $-E_{l}$ lost during a cycle, dissipated because the internal friction $\left(E_{l}=0.02285 \mathrm{~N} \cdot \mathrm{m}\right)$. The input mechanical energy $-E_{i}$ during the loading process used for deformation (calculated as the area between the red curve and horizontal line - $h l$ on Figure 5, $\left.E_{i}=0.197795 \mathrm{~N} \cdot \mathrm{m}\right)$ is bigger than the output mechanical energy $-E_{o}$ delivered by the gripper jaw during unloading process (calculated as the area between the blue curve and horizontal line $h l$ on Figure 5, $\left.E_{o}=0.174941 \mathrm{~N} \cdot \mathrm{m}\right)$. The difference between these two energies is evidently the lost mechanical energy $E_{l}$ as $E_{l}=E_{i}-E_{o}$. Both areas (energies) were calculated here by numerical integration. 
The energy $E_{l}$ can be a cumulative characterization of the behaviour of material and the gripper jaw shape during a loading/unloading cycle. We propose two more appropriate characterizations:

-The ratio between the energy $E_{l}$ and the variation of force (the amount of mechanical energy lost per unit of force, $\left.E_{l f}=4.455 \cdot 10^{-4} \mathrm{Nm} / \mathrm{N}\right)$, with meter as measurement unit.

The ratio between the energy $E_{l}$ and the variation of deformation (the amount of mechanical energy lost per unit of deformation, $E_{l d}=3.2207 \mathrm{Nm} / \mathrm{m}$ ), with Newton as measurement unit.

Thus $E_{l f d o e s}$ not depend by applied force and $E_{l d}$ does not depend by deformation.
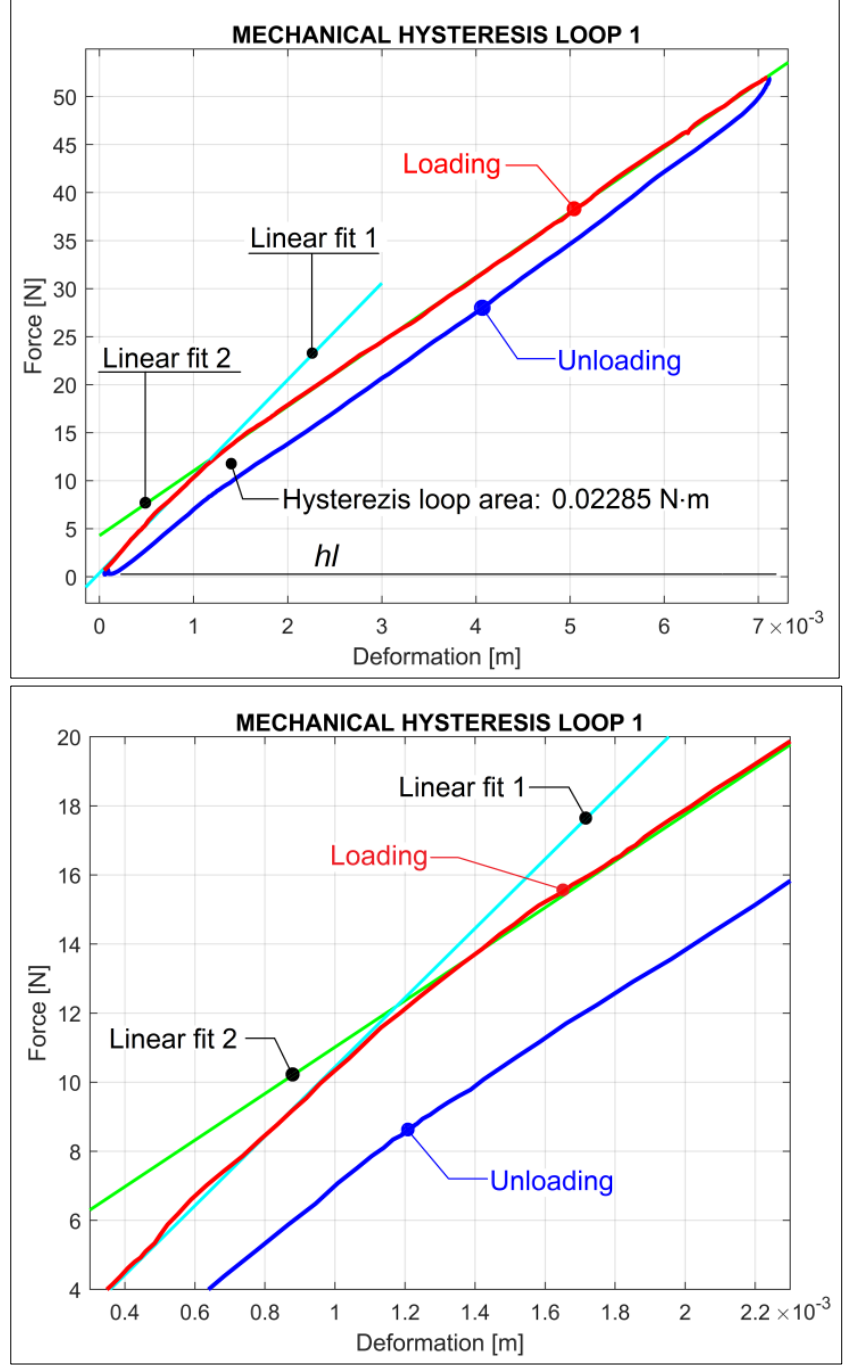

Figure 5. The description of first mechanical hysteresis loop $\left(E_{l f}=4.455 \cdot 10^{-4} \mathrm{Nm} / \mathrm{N}\right.$, $E_{l d}=3.2207 \mathrm{Nm} / \mathrm{m}, k_{1}=10032.7$ $\left.\mathrm{N} / \mathrm{m}, k_{2}=6734.5 \mathrm{~N} / \mathrm{m}\right)$
Figure 6.A zoom-in detail on Figure 2 (in the area of fitting line intersection)

Second important experimental information on Figure 5 is the average bending stiffness of the gripper jaw (depending by material type, material structure, shape and loading) as the slope of the line which produces the best approximation (by computer assisted linear curve fitting, or by least square regression as well) of the evolution of force versus deformation, during loading process.

It is interesting that the loading cycle can be easily approximated with two lines by curve fitting (as Figures 5 and 6 indicate). First line, from linear fit 1 (for a loading range $0 \div 12 \mathrm{~N}$ ) is defined (with the slope-intercept formula $F=k_{1} d+F_{01}$ of fitting line) by:

$$
F=10032.7 \cdot d+0.406
$$

Second line, from linear fit 2 (for loading bigger than $12 \mathrm{~N}$ ) is defined (with the slope-intercept formula $F=k_{2} d+F_{02}$ ) by: 
$F=6734.5 \cdot d+4.281$

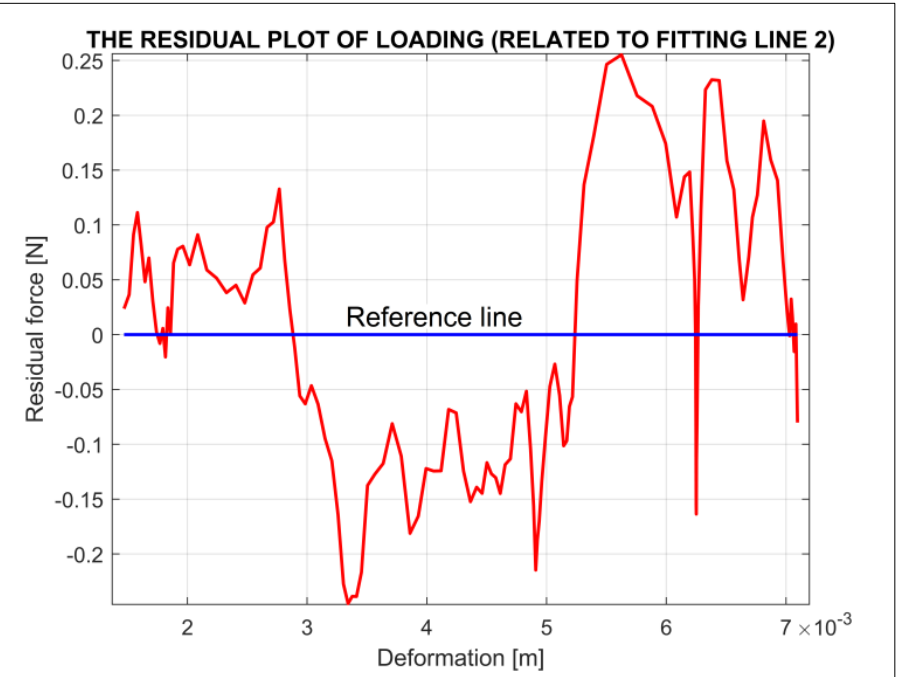

(2)

Figure 7. The residual plot of loading curve from Figure 2 related to fitting line $2( \pm 0.25 \mathrm{~N})$

This means that -with a good approximation- the gripper jaw has two value of stiffness: $k_{l}=10032.7$ $\mathrm{N} / \mathrm{m}$ (for a loading smaller than $12 \mathrm{~N}$ ) and $k_{2}=6734.5 \mathrm{~N} / \mathrm{m}$ for a loading bigger than $12 \mathrm{~N}$. The intercept of first linear fit (the intersection of first fitting line with y-axis) is the remnant force $F_{01}=0.406 \mathrm{~N}$. The intercept of second linear fit (the intersection of second fitting line with y-axis) is the remnant force $F_{02}=4.281 \mathrm{~N}$.

It is also interesting to underline the value of the ratio $E_{l d} / E_{l d}=7229.56 \mathrm{~N} / \mathrm{m}$ : it has the same measurement unit as the stiffness and is relative close by $k_{2}$ value.

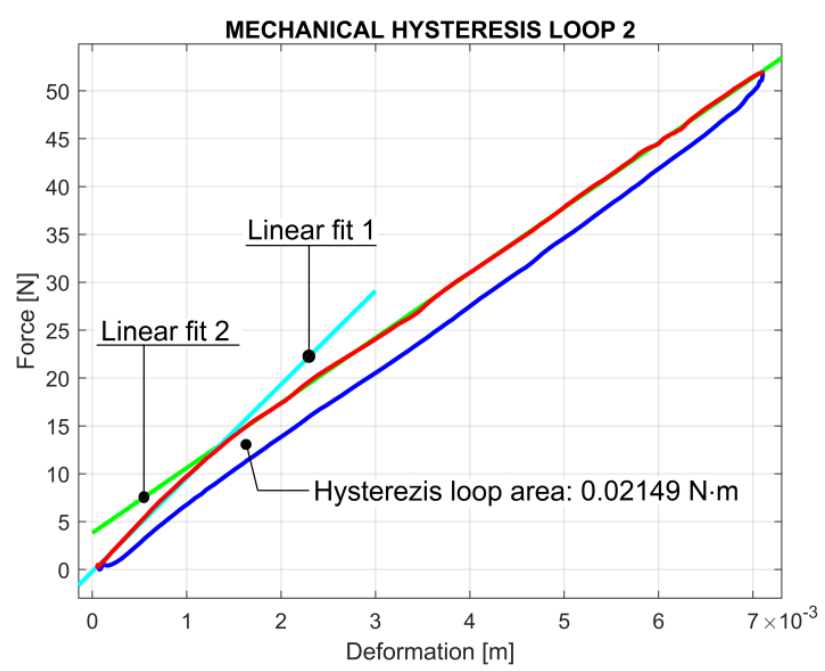

Figure 8. The description of secondmechanical hysteresis loop $\left(E_{l f}=4.161 \cdot 10^{-4} \mathrm{Nm} / \mathrm{N}, E_{l d}=3.0250 \mathrm{Nm} / \mathrm{m}\right.$, $\left.k_{1}=9771.3 \mathrm{~N} / \mathrm{m}, k_{2}=6793.0 \mathrm{~N} / \mathrm{m}\right)$

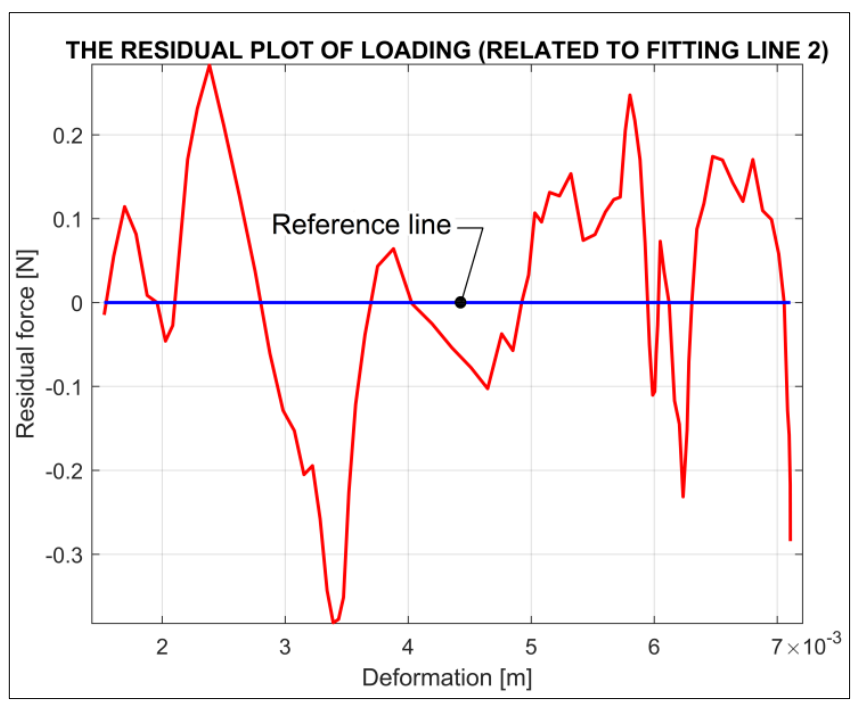

Figure 9.Theresidual plot of loading curve from Figure 5 related to fitting line 2

It is obvious that the evolution of loading related to linear fit 2 on Figure 5, and the residual plot of loading curve from Figure 7 too (here the reference line depicts the line from linear fit 2) proves a good linearity (with the variation of residual force of $\pm 0.25 \mathrm{~N}$ ). 
An analysis of the other two hysteresis loops from Figure 4 produces similar results. Figure 8 describes the second hysteresis loop and fitting lines, Figure 9 describes the residual plot of Figure 8.

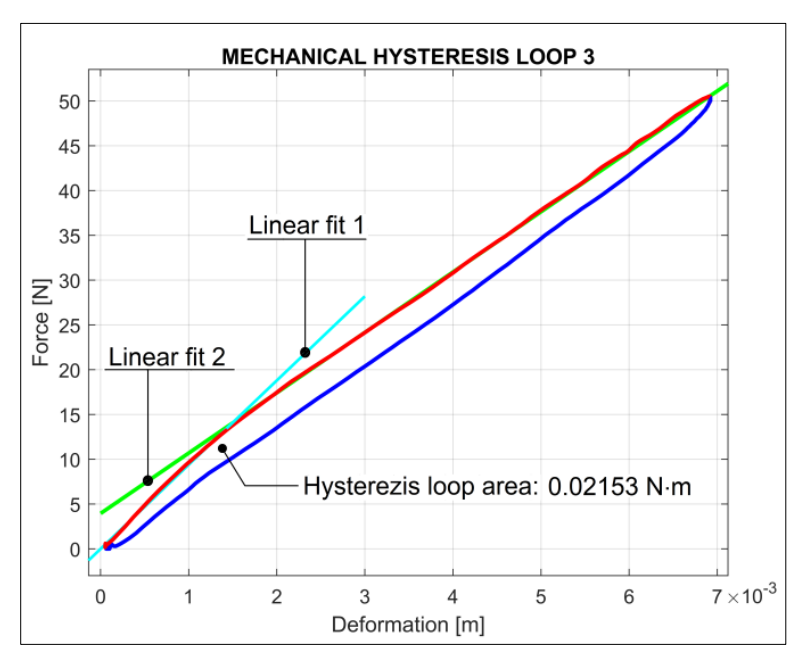

Figure 10. The description of third mechanical hysteresis loop $\left(E_{l f}=4.277 \cdot 10^{-}\right.$ ${ }^{4} \mathrm{Nm} / \mathrm{N}, E_{l d}=3.1105 \mathrm{Nm} / \mathrm{m}, k_{1}=9398.8 \mathrm{~N} / \mathrm{m}$, $\left.k_{2}=6774.9 \mathrm{~N} / \mathrm{m}\right)$

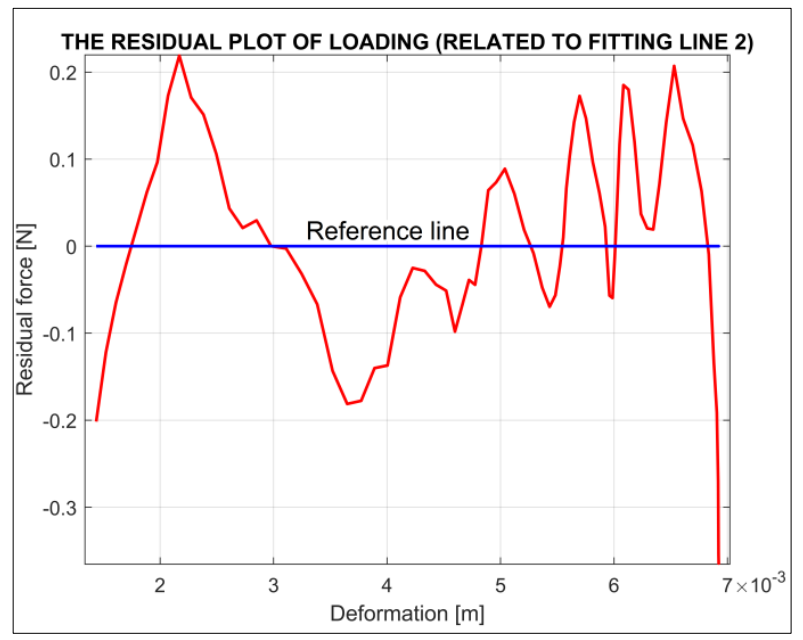

Figure 11. The residual plot of loading curve from Figure 7 related to fitting line 2

Figure 10 describes the second hysteresis loop and fitting lines, Figure 11 describes the residual plot of Figure 10.

The main experimental results for each mechanical hysteresis loop are described in Table 2.

Table 2. Main experimental results for each mechanical hysteresis loop

\begin{tabular}{|c|c|c|c|c|c|c|c|}
\hline Loop \# & $\begin{array}{c}k_{l} \\
{[N / m]}\end{array}$ & $\begin{array}{c}k_{2} \\
{[N / m]}\end{array}$ & $\begin{array}{c}E_{l} \\
{[N \cdot m]}\end{array}$ & $\begin{array}{c}E_{l f} \\
{[m]}\end{array}$ & $\begin{array}{c}E_{l d} \\
{[N]}\end{array}$ & $\begin{array}{c}E_{l d} / E_{l f} \\
{[N / m]}\end{array}$ & $\begin{array}{c}r=\left(E_{l d} / E_{l f}\right) / k_{2} \\
{[]}\end{array}$ \\
\hline$\# 1$ & 10032.7 & 6734.5 & 0.02285 & $4.455 \cdot 10^{-4}$ & 3.2207 & 7229.56 & 1.0735 \\
\hline$\# 2$ & 9771.3 & 6793.0 & 0.02149 & $4.161 \cdot 10^{-4}$ & 3.0250 & 7269.01 & 1.0700 \\
\hline$\# 3$ & 9398.8 & 6774.9 & 0.02153 & $4.277 \cdot 10^{-4}$ & 3.1105 & 7297.41 & 1.0732 \\
\hline Average & $\mathbf{9 7 3 4 . 2}$ & $\mathbf{6 7 6 7 . 4}$ & & $\mathbf{4 . 2 9 7 \cdot 1 0 ^ { - 4 }}$ & $\mathbf{3 . 1 1 8 7}$ & $\mathbf{7 2 6 5 . 3 2}$ & $\mathbf{1 . 0 7 2 2}$ \\
\hline
\end{tabular}

There are two important observations in Table 2:

-There are relative small variations of the stiffness $k_{2}$. The average value of bending stiffness $k_{2}(6767.4 \mathrm{~N} / \mathrm{m})$ should be considered as the best option in gripper jaw behaviour characterization.

-There are also relative small variations of the ratio $E_{l d} / E_{l f}$. As it proved in the last column from Table 2 , this ratio seems to be strictly related by the bending stiffness $k_{2}$ (here with average value of the dimensionless ratio $r=\left(E_{l d} / E_{l f}\right) / k_{2}=1.0722$ ). The value of the ratio $E_{l d} / E_{l f}$ (having the same unit of measurement as bending stiffness $k_{2}$ ) seems to be a type of stiffness involved in gripper jaw characterization(or any other mechanical part tested in the same way). A future approach will be focused on this topic. Also the signification of the ratio $r$ will be privileged in a future research.

In order to characterize the behaviour of the 3D printed gripper jaws a finite element analysis was performed, considering the experimental input force values of $52 \mathrm{~N}$ and the experimental used measuring scheme.

The definition of ABSplus-P430 material, used by the Stratsys 250 mc printer, in the ANSYS software, a generic acrylonitrile butadiene styrene (ABS) material, from the information database, was selected and the values for ABSplus-P430 were introduced, the main difference was the values of Young module $2200 \mathrm{MPa}$ [12], and flexural modulus is $1.6 \mathrm{GPa}$.

The loading scheme is presented in Figure 12. The areas represented in blue represent Fixed Support 
(or recess), and the force of $52 \mathrm{~N}$. was applied at the top of the part in the direction given by the blue arrow (according to the experiment).

Figure 13 presents the Equivalent Stress (Von Mises) distribution for a modulus of $1.5 \mathrm{GPa}$.

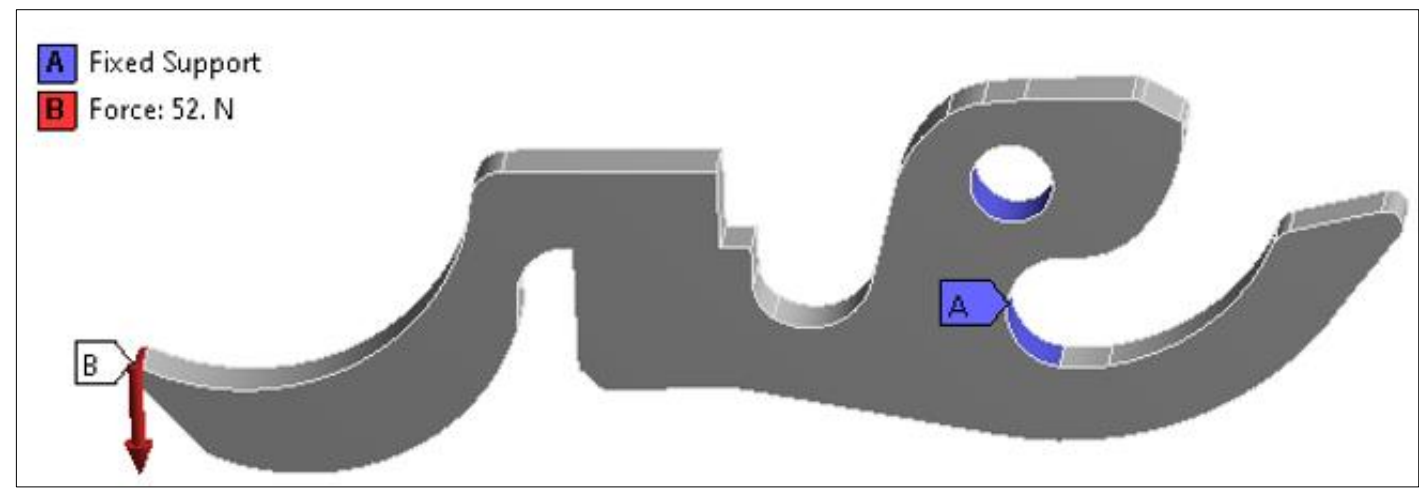

Figure 12. FEA loading and support

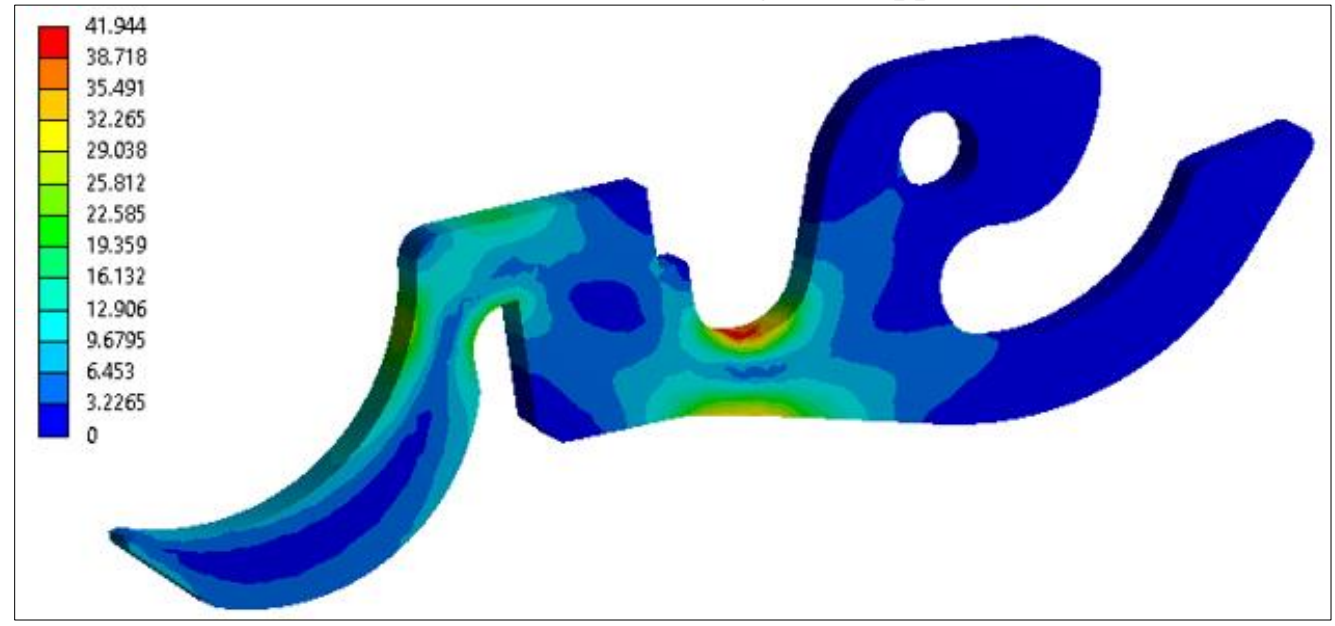

Figure 13. Equivalent Stress (Von Mises) distribution

From the current research the printing parameters have a large impact on the mechanical properties of the 3D printed parts. From the current research the mechanical properties of the $3 \mathrm{D}$ printed parts are usually lower by $15-26 \%$ from the manufacturer datasheet specification of the material $[6,9,10,11]$. According to Stratasys the 3D printed prototype has up to $80 \%$ of the strength of injection moulded ABS material [12].

Considering the current research on the mechanical properties of the materials FDM, several finite element analysis were done by varying Young modulus in accordance with the experimental results presented in the literature - 1.5 GPa ,1.57 GPa, 1.6 GPa, 1.7 GPa, 1.8 GPa, 2 GPa, 2.15 GPa.

Figure 14 presents FEA displacement results in the measuring area.

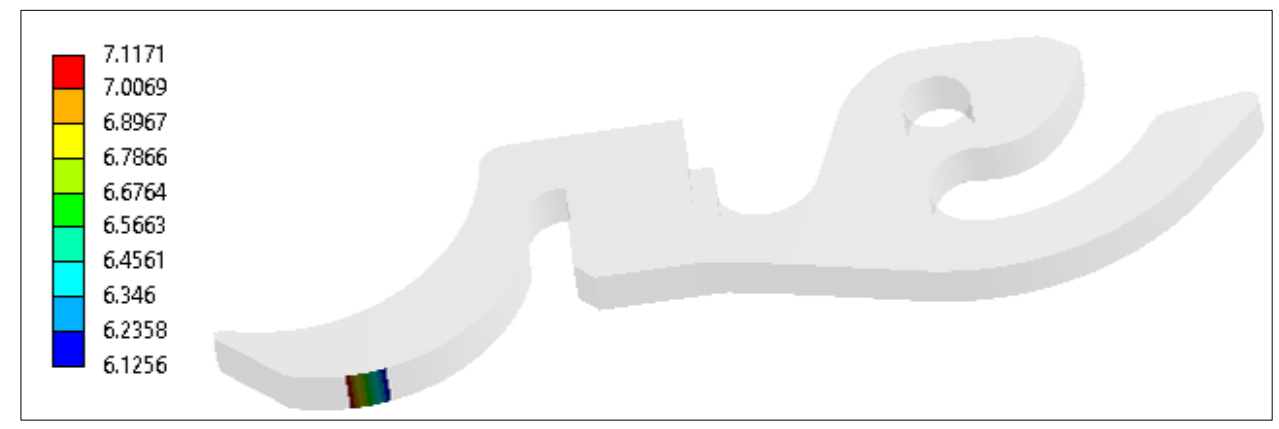

Figure 14. FEA displacement results in the measuring area for a modulus of $1.8 \mathrm{GPa}$ 
The FEA results for 52N load and variation of Young module are presented in Figure 15. The FEA value that is the closest to the experimental values is corresponding to a Young modulus of $1.8 \mathrm{GPa}$, resulting a deformation of $7.11 \mathrm{~mm}$.

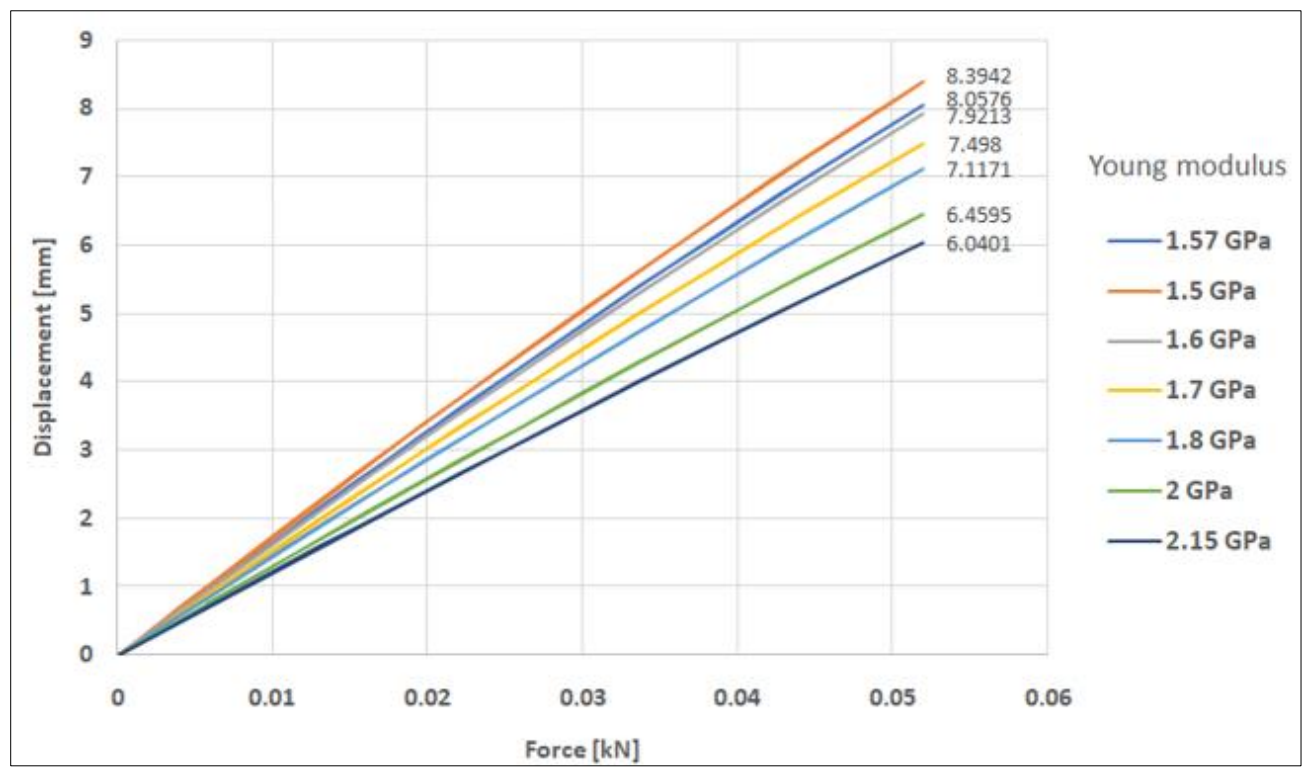

Figure 15. Evolution of deformations (stiffness) for the gripper jaw, considering different Young module, for $0.052 \mathrm{kN}$ load

\section{Conclusions}

The paper presents the measured values for displacement of 3D printed gripper jaws - soft jaws, considering normal working conditions of type of parts. In the performed experiment a modified jaw, in order to clamp a soda can, was 3D printed with $100 \%$ infill, from a De-sta-co gripper model De-sta-co 84A3-3300AAAA.

Several loading - unloading cycles were made and the stiffness value was determined. An analysis of the hysteresis loops indicate that loading cycle can be easily approximated with two lines by curve fitting and two values of the stiffness can be calculated, thus proving a nonlinear behaviour of the 3D printed jaws. The area of the hysteresis cycle between the loading curve and the unloading curve represents the mechanical work not recovered from the system.

A finite element analysis was performed considering the experimental loading and support conditions and the Young modulus was varies considering the values proposed in the literature between $1.5 \mathrm{GPa}$ to $2.15 \mathrm{GPa}$. The values for displacement that are closer to the experimental values are corresponding to a value of $1.8 \mathrm{GPa}$ for Young modulus, value that is $18 \%$ lower that Young modulus for a part obtained by injection moulding.

Printing parameters can be selected in order to maximize the mechanical properties of the parts, but when working with complex parts the distribution of loads and stress varies during the work process. For complex parts FEA is a fast and reliable method for determining the strain and stress but in order to safely design and simulate the behaviour of 3D printed parts, lower values for Young modulus must be considered. From the specialized literature and perform experiments, Young modulus for 3D printed parts when designing a complex parts with complex working conditions, should be $20-25 \%$ lower that the injection moulding.

Acknowledgments: This work was accomplished with the support of COMPETE project nr. 9PFE/2018, funded by the Romanian Government

\section{References}

1. BOYES,W., (ed.), Handbook of Jig and Fixture Design, Dearborn, Michigan, SME, 1989. 
2. POPESCU, A., ENCIU, G., DOBRESCU, T., PASCU, N.E., Experimental Research Using the 3D Printing Technology with Plastic Materials for Prehension Systems Jaws, Mater. Plast., 55(1), 2018, 20 23., DOI: $10.37358 / M P .18 .1 .4955$.

3. LIM, S., BUSWELL, R.A., LE, T.T., AUSTIN, S.A., GIBB, A.G.F., THORPE, T., Developments in construction-scale additive manufacturing processes, Automation in Construction, 21 (1), 2012, pp. 262268.

4. HUANG, Y., MING, M., JYOTI, D., Additive Manufacturing: Current State, Future Potential, Gaps and Needs, and Recommendations. Journal of Manufacturing Science and Engineering, 137, 2015, https://doi.org/10.1115/1.4028725.

5.VANEKER, T., BERNARD, A., MORONI, G., GIBSON, I., ZHANG, Y., Design for additive manufacturing: Framework and methodology, CIRP Annals, 2020, ISSN 0007-8506,

https://doi.org/10.1016/j.cirp.2020.05.006

6. DUDESCU, C., RACZ, L., Effects of Raster Orientation, Infill Rate and Infill Pattern on the Mechanical Properties of 3D Printed Materials. ACTA Universitatis Cibiniensis, 69,2017, https://doi.org/10.1515/aucts-2017-0004.

7. CHITARIU, D., F., MUNTEANU, A., Research on 3D printed fixture components, MATEC Web of Conferences 178, 02008, 2018 https://doi.org/10.1051/matecconf/201817802008,

8. WU, W.; GENG, P.; LI, G.; ZHAO, D.; ZHANG, H.; ZHAO, J. Influence of Layer Thickness and Raster Angle on the Mechanical Properties of 3D-Printed PEEK and a Comparative Mechanical Study between PEEK and ABS, Materials, 2015, 8, 5834-5846, https://doi.org/10.3390/ma8095271.

9. ZIEMIAN, C., SHARMA. M., ZIEMIAN, S., Anisotropic Mechanical Properties of ABS Parts Fabricated by Fused Deposition Modelling, Mechanical Engineering, Murat Gokcek, IntechOpen, DOI: 10.5772/34233. Available from:

https://www.intechopen.com/books/mechanical-engineering/anisotropic-mechanical-properties-of-absparts-fabricated-by-fused-deposition-modeling.

10. ABEYKOON, C. et al. Optimization of fused deposition modelling parameters for improved PLA and ABS 3D printed structures, International Journal of Lightweight Materials and Manufacture, 3, 2020, pp. 284-297, https://doi.org/10.1016/j.ijlmm.2020.03.003.

11. AHMED, M., I., VANHOOSE M., HEWAVITHARANA, J., STANICH L., HOSSAIN, A., (2016). Comparisons of Bending Stiffness of 3D Printed Samples of Different Materials.

https://doi.org/10.1115/IMECE2016-65119.

12.***ABS plus p-430 Datasheet Available online https://support.stratasys.com/en/materials/fdmmaterials/absplus-p430, (accessed on 11.06.2020)

Manuscript received: 22.11 .2020 